Epidemiology, disease patterns, immunology, diagnosis, treatment and control measures of leishmaniasis are described. Various issues relating to leishmaniasis are highlighted: the relative lack of importance given to this disease compared with other infections, climate change and its possible impact on extension of endemicity of this infection, and new diagnostic tests which are improving diagnosis, especially in resource poor areas. Other important aspects discussed include the potential for newer oral therapy to change the way this disease is managed; Leishmania-HIV coinfection and groups at risk; and development of an effective vaccine.

\section{Publisher's apology}

This article is being reprinted as there were a number of errors in the original version. The publisher apologises unreservedly to the authors and readers for any confusion these errors may have caused.

See end of article for authors' affiliations

Correspondence to: Dr T V Piscopo, Sir Temi Zammit Infectious Disease Unit, St Luke's Hospital, Guardamangia Hill, Guardamangia, MŚD 09, Malta; tonio.piscopo@gov. $\mathrm{mt}$

Received 2 March 2006 Accepted 15 May 2006 nfectious diseases steal the headlines on a regular basis and are ranked high among other major news items like natural disasters, conflict situations and terrorism. Emerging infectious diseases with wide threatening potential such as severe acute respiratory syndrome and pandemic influenza, are usually the ones which get best coverage and consequently better funding. Diseases with high prevalence such as HIV/AIDS and malaria (table 1) should bring better financial returns from investing research into new treatments and developing vaccinations than similar investment into lower prevalence infections. Leishmaniasis is one such infection which rarely shares this limelight and thus remains largely a neglected disease. ${ }^{12}$

Despite this, several issues regarding leishmaniasis merit discussion: resistance to conventional drug treatment has developed in certain areas of the world, necessitating a change of first-line agents; rapid, less invasive diagnostic procedures have been developed which are most useful in poorly resourced parts of the world; despite advances in the understanding of the immunology of the disease and the unravelling of the Leishmania genome, a vaccine has not yet been developed; and the extent of disease in different individuals stresses the complex immunology of leishmaniasis, brought to the fore more recently with the advent of HIV-Leishmania coinfection, and its difficult eradication in this scenario.

This review is based on information from bibliographic research, Entrez-Pubmed searches on leishmaniasis, review articles and papers in their reference lists, and from the authors' personal archives.

\section{EPIDEMIOLOGY}

Leishmaniasis is endemic in more than 60 countries worldwide, ${ }^{1}$ including Southern Europe, North Africa, the Middle East, Central and South
America and the Indian subcontinent. It is not endemic in South East Asia and Australia. ${ }^{4}$ The burden of disease (90\% of cases) is borne by Afghanistan, Pakistan, Syria, Saudi Arabia, Algeria, Iran, Brazil, and Peru in the case of cutaneous leishmaniasis, and by India, Bangladesh, Nepal, Sudan, and Brazil in the case of visceral leishmaniasis. ${ }^{3}$ Recently the number of reported cases and geographical areas have increased, ${ }^{5}$ and this has sparked concern regarding the contribution that global warming might have on this observation. ${ }^{67}$

One of the causative organisms of leishmaniasis, Leishmania donovani, was first described in 1903 by Leishman and Donovan almost simultaneously. ${ }^{4}$ Leishmania is a protozoon, able to infect animals, humans and sandflies. There are at least 20 species of Leishmania. Each may cause a disease specific to the species and the host response. Organism prevalence differs by geographical distribution. Thus disease patterns differ by geographical area (table 2).

The reservoirs of the disease are animals like canines and rodents (zoonotic cycle) and, in countries such as Sudan, humans (anthroponotic cycle). ${ }^{10}$ The sandfly is the vector of the disease and ingests the organism, as an amastigote, into its digestive tract when feeding on an infected animal. The amastigote develops into a promastigote in its digestive tract, and will then be injected into the susceptible host at the next feed. The promastigote then infects macrophages and develops into amastigotes (fig 1).

About 70 different species of sandfly can transmit leishmaniasis. ${ }^{11}$ The species are mainly Lutzomyia in the Americas and Phlebotomous elsewhere. $^{12}$ The sandfly characteristically feeds at dusk, and being a weak flier, tends to remain close to its breeding area, not too high from the ground. Different species have different feeding and resting patterns. These different characteristics are important in formulating control strategies (see below).

The incidence and prevalence can be seen in table 1 . Infection is more common in men than in women, but this may reflect increased exposure to sandflies. Although disease occurs irrespective of age, children aged 1-4 years are particularly at risk of infection in the Mediterranean regions, and childhood infection may account for more than half of all cases in some of these countries. ${ }^{13}$ Untreated visceral leishmaniasis carries a mortality of $75-95 \%$, while cutaneous leishmaniasis can

Abbreviations: IFN, interferon; PCR, polymerase chain reaction; PKDL, post-kala azar dermal leishmaniasis; Th, T helper 
Table 1 Epidemiology of different infectious diseases

\begin{tabular}{|c|c|c|c|}
\hline Disease & $\begin{array}{l}\text { Annual } \\
\text { incidence } \\
\text { (global) }\end{array}$ & $\begin{array}{l}\text { Mortality: no of } \\
\text { deaths per year } \\
\text { (global) }\end{array}$ & $\begin{array}{l}\text { Prevalence: total } \\
\text { no of infected } \\
\text { persons (global) }\end{array}$ \\
\hline HIV/AIDS & 5.6 million & 2.6 million & 34 million \\
\hline Malaria & 300 million & $1-2.7$ million & - \\
\hline Tuberculosis & 7.8 million & 1.8 million & 1.7 billion \\
\hline $\begin{array}{l}\text { Visceral } \\
\text { leishmaniasis }\end{array}$ & 500000 & 80000 & 12 million \\
\hline $\begin{array}{l}\text { Cutaneous } \\
\text { leishmaniasis }\end{array}$ & $1.5-2$ million $^{3}$ & - & - \\
\hline
\end{tabular}

disseminate to involve the mucosa, resulting in death from secondary infection. ${ }^{8}$

\section{DISEASE PATTERNS}

Three main types of disease patterns occur: visceral, cutaneous and mucocutaneous leishmaniasis (table 3 ). The type of disease expressed depends both on the type of Leishmania species and on the zymodeme (electrophoretic isoenzyme pattern) expressed on that species. Thus one zymodeme may cause visceral leishmaniasis while another zymodeme of the same species may cause cutaneous leishmaniasis. ${ }^{14}$

\section{Visceral leishmaniasis}

The incubation period varies from 3 to 8 months $^{15}{ }^{16}$ (range 10 days ${ }^{17}$ to 34 months $^{18}$ ). Features include fever, weight loss, hepatosplenomegaly (usually spleen much larger than liver), lymphadenopathy, pancytopenia and hypergammaglobulinaemia. ${ }^{10}$ Skin pigmentation may be a feature ("kala azar": black disease). It may be asymptomatic and self-resolving, but usually runs a chronic course and may be fatal without or despite treatment. ${ }^{19}$ Death usually occurs because of severe secondary bacterial infections in advanced disease.

Some cases of visceral leishmaniasis present atypically and cases have been reported which involve the lungs, pleura, oral

\section{Box 1: Current issues in Leishmania infection}

- Leishmania is given less importance than other more prevalent infectious diseases.

- Climate change may be responsible for the extension of endemicity of leishmaniasis to previously non-endemic countries.

- New diagnostic tests should improve diagnosis, especially in the field in resource-poor areas.

- Leishmania may relapse in HIV patients and is difficult to eradicate, if at all in this setting. There have been calls for Leishmania infection to be officially recognised as an AIDS-defining illness.

- Anthroponotic transmission may occur in intravenous drug users who share needles.

- The Leishmania genome has been unravelled, but an effective vaccine is not yet available.

mucosa, larynx, oesophagus, stomach, small intestine, skin and bone marrow.$^{12}$

\section{Variations of visceral leishmaniasis}

Post-kala azar dermal leishmaniasis (PKDL) develops after resolution of visceral leishmaniasis. The time interval to development of PKDL is variable. PKDL occurs in a small percentage of patients in Africa and India. ${ }^{12}$ This is usually due to infection by the $L$ donovani sensu stricto cluster. ${ }^{20}$ The skin lesions are macular, maculo-papular or nodular, and usually spread from the perioral area to other areas of the body.

\section{Cutaneous leishmaniasis}

This initially starts as a papule at the site of a sandfly bite which then increases in size, crusts (fig 2), and eventually ulcerates. It may take 3-18 months to heal in over $90 \%$ of cases. ${ }^{12}$ The incubation period lasts from 2 weeks to several months and cases up to 3 years have been reported in Old World cutaneous

Table 2 Disease patterns and organisms prevalent in different geographical locations ${ }^{4} 812$

\begin{tabular}{|c|c|c|}
\hline Disease patterns & Old World organisms & New World organisms \\
\hline Visceral leishmaniasis & $\begin{array}{l}L \text { donovani (India, Kenya) } \\
L \text { infantum (Southern Europe and } \\
\text { North Africa) } \\
L \text { tropica }\end{array}$ & $\begin{array}{l}\text { L chagasi } \\
\text { L amazonensis }\end{array}$ \\
\hline Post-kala azar dermal leishmaniasis & L donovani sensu stricto & \\
\hline Viscerotropic leishmaniasis & L tropica & \\
\hline Cutaneous leishmaniasis & $\begin{array}{l}L \text { tropica } \\
L \text { major } \\
L \text { aethiopica } \\
L \text { infantum } \\
L \text { donovani }\end{array}$ & $\begin{array}{l}\text { L mexicana species complex } \\
\text { L mexicana } \\
\text { L amazonensis } \\
\text { L venezuelensis } \\
\text { Viannia subgenus } \\
\text { L (V) braziliensis } \\
L(V) \text { panamensis } \\
L(V) \text { guyanensis } \\
L \text { (V) peruviana) } \\
\text { L major-like organisms } \\
\text { L chagasi }\end{array}$ \\
\hline Mucosal leishmaniasis & $\begin{array}{l}\text { Viannia subgenus } \\
\text { L (V) braziliensis } \\
\text { L (V) panamensis } \\
L(V) \text { guyanensis) } \\
\text { L amazonensis (see text) }\end{array}$ & \\
\hline Leishmaniasis recidivans & $\begin{array}{l}\text { L tropica } \\
\text { L major }\end{array}$ & \\
\hline Diffuse cutaneous leishmaniasis & L aethiopica & L mexicana species complex \\
\hline
\end{tabular}

(V): refers to the Viannia subgenus. The leishmanias were classified into the subgenera Leishmania sensu stricto (Old and New World) and Viannia (New World) by Lainson and Shaw in 1987.? 


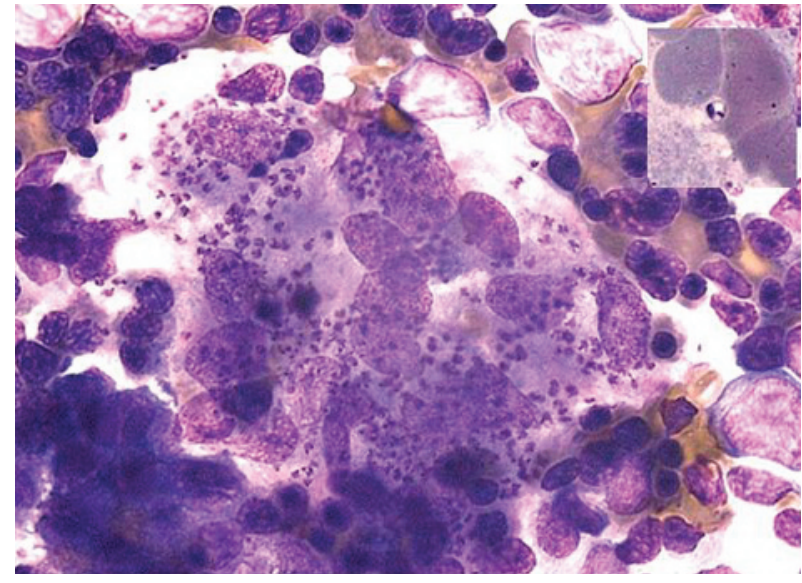

Figure 1 Abundant amastigotes of Leishmania in a bone marrow aspirate. Inset photo showing amastigote with its nucleus and kinetoplast (specialised mitochondria containing DNA) (photograph courtesy of Dr Alicia Grochowska, Consultant Haematologist, St Luke's Hospital, Malta).

leishmaniasis. ${ }^{17} 21$ In New World cutaneous leishmaniasis, the incubation period is usually $2-8$ weeks. ${ }^{22}$

\section{Variations of cutaneous leishmaniasis}

Leishmaniasis recidivans is characterised by tuberculoid lesions developing around scars of healed cutaneous ulcers, revealing a low parasite count on biopsy. Infections tend to be resistant to treatment.

In diffuse cutaneous leishmaniasis, dissemination of skin lesions rarely occurs over the face, hands and feet, revealing high parasite numbers due to poor cell-mediated immune response. This is more common in the New World Leishmania but also occurs with $L$ aethiopica in East Africa. ${ }^{23}$

\section{Mucocutaneous leishmaniasis}

The incubation period is $1-3$ months, but mucocutaneous leishmaniasis may occur many years after the initial cutaneous ulcer has healed. Mucosal involvement occurs in South American cases of cutaneous leishmaniasis (espundia) involving the nose, oral cavity and pharynx. This causes difficulty with eating and an increased risk of secondary infection which carries a significant mortality.

\section{IMMUNOLOGY}

The immune response (box 2) to Leishmania infection is cell mediated. The organism lies exclusively intracellularly, mainly inside macrophages as replicating amastigotes. The outcome of

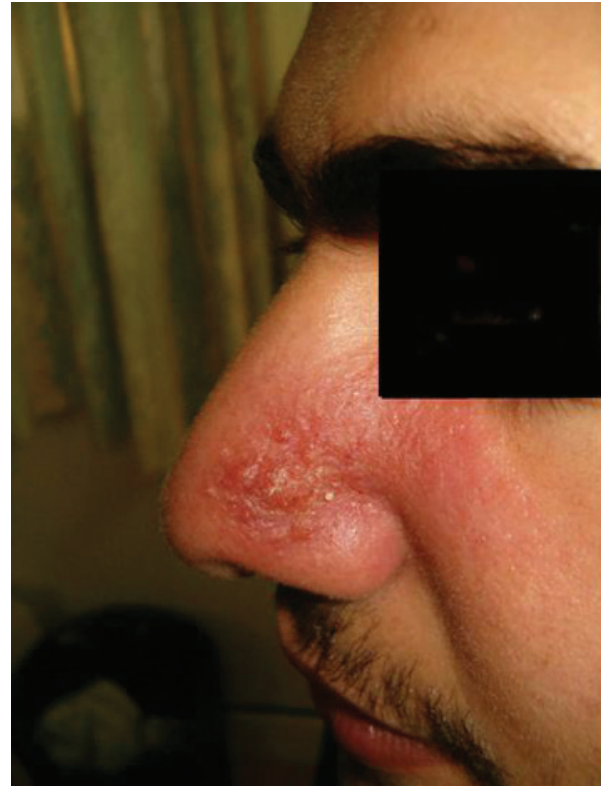

Figure 2 Cutaneous leishmaniasis at crusting stage, Malta (informed consent was obtained from the patient to publish this photograph).

infection will depend on whether the host mounts primarily a T-helper (Th)-1 or Th2 response. ${ }^{24}$ Studies in animals suggest that the same parasite epitope can induce a Thl response in animals with resolving infection or a Th2 response in others with disease progression. ${ }^{25}$ Other animal studies have shown that Thl and natural-killer cells produce interferon $\gamma$ (IFN $\gamma$ ), which mediates resistance, whilst interleukin (IL)4-producing Th2 cells confer susceptibility to infection. ${ }^{26}$ Human studies have also shown that IL4, a component of the Th2 response, may also be associated with disease progression. ${ }^{27}$

In the Thl response, promastigotes attach to reticuloendothelial cells and T helper CD4 cells produce IL2, IL3 and IFN $\gamma$ which activate macrophages. IL12 and tumour necrosis factor (TNF) are also important in this type of response. The promastigotes are then phagocytosed by the activated macrophages into vacuoles which then fuse with lysosomes.

Host genetics inevitably influence the type of immune response. Studies in mice and humans have shown that genes such as those coding for natural resistance associated macrophage protein 1 (NRAMPl), TNF or the major histocompatibility complex are thought to play a major role in the outcome of infection. ${ }^{28}$ The parasite itself can affect the macrophage and

Table 3 Leishmaniasis disease patterns

\begin{tabular}{|c|c|c|}
\hline Disease type & Incubation period & Clinical features \\
\hline Visceral leishmaniasis & 3- 8 months (range 10 days to 34 months) & $\begin{array}{l}\text { Fever, weight loss, hepatosplenomegaly lymphadenopathy, } \\
\text { pancytopenia and hypergammaglobulinaemia, skin pigmentation }\end{array}$ \\
\hline Post-kala azar dermal leishmaniasis & $\begin{array}{l}\text { Variable; develops after resolution of visceral } \\
\text { leishmaniasis }\end{array}$ & Skin lesions around mouth and other parts of body \\
\hline Cutaneous leishmaniasis & 2 weeks to several months (rarely up to 3 years) & $\begin{array}{l}\text { Papule at the site of a sandfly bite increases in size, crusts, and } \\
\text { ulcerates }\end{array}$ \\
\hline Leishmaniasis recidivans & & $\begin{array}{l}\text { Tuberculoid lesions develop around scars of healed cutaneous ulcers; } \\
\text { low parasite count on biopsy }\end{array}$ \\
\hline Diffuse cutaneous leishmaniasis & & $\begin{array}{l}\text { Rare. Dissemination of skin lesions occurs over face and extremities; } \\
\text { high parasite numbers due to poor cell-mediated immune response }\end{array}$ \\
\hline Mucocutaneous leishmaniasis & $\begin{array}{l}1-3 \text { months (may occur many years after the } \\
\text { initial cutaneous ulcer has healed) }\end{array}$ & $\begin{array}{l}\text { Mainly in South America. Involves the nose, oral cavity and pharynx } \\
\text { resulting in difficulty with eating }\end{array}$ \\
\hline
\end{tabular}




\section{Box 2: The immune response}

Th 1 immune response

- T-helper CD4 cells producing IL2, IL3, IFN $\gamma$

- Will promote immune responses that are primarily cell mediated/inflammatory by activating cytotoxic $T$ cells, natural killer cells and macrophages

- In leishmaniasis, associated with disease resolution

Th2 immune response

- Th2 cells produce IL4, IL5, IL6, IL10 which favour induction of antibody responses by $B$ cells

- In leishmaniasis, associated with disease progression

dendritic cell responses. Specific gene loci such as the A2 gene can code for products which promote $L$ donovani infectivity. ${ }^{11}$ Thus the interplay between the host-determined delayed-type hypersensitivity, antigen-specific T-cell reactivity, and cytokine secretion, and the type and virulence of the particular infecting Leishmania species determine what type of disease expression develops in the host.

Some cases are believed to harbour Leishmania organisms for indefinite periods before the disease is expressed, suggesting latent infection..$^{29}$ Parasites have also been detected in lymph nodes after clinical cure. ${ }^{30}$ This is probably the basis of recrudescence of leishmaniasis which can occur decades after the initial infection, if cell-mediated immunity becomes disturbed. It is thought that "sterile" immunity-that is, complete eradication of the organism, probably rarely develops in visceral infection.

\section{DIAGNOSIS}

\section{Visceral leishmaniasis}

Diagnosis in visceral leishmaniasis is usually based on microscopic detection of amastigotes in smears of tissue aspirates or biopsy samples. Bone marrow aspirates or biopsy are frequently the tissues of choice with sensitivities in the 55-97\% range (fig 1). Lymph node aspirate smears (sensitivity 60\%) or biopsy, and splenic aspirates ( diagnosis, though the latter may give rise to life-threatening haemorrhage (table 4).

Sometimes the parasite can be cultured from microscopy negative tissue samples on special media like Novy, McNeal, Nicolle (NNN) medium or inoculated into animals such as hamsters.

Leishmania antibody (direct agglutination test) may be detected with a sensitivity of $72 \%$ and a specificity of $94 \% .{ }^{10}$ Some cross-reactions in leprosy, Chagas disease, malaria, and schistosomiasis may occur. In HIV, antibodies to Leishmania may become undetectable.

Immunochromatographic strip testing of blood from a finger prick for leishmanial anti-K39 antibody has been used successfully in field serodiagnosis ${ }^{31}$ with a sensitivity of 90 $100 \%$ in symptomatic patients. This test is useful in clinical management in resource-poor areas. ${ }^{1}$

Leishmania DNA can also be detected in tissue aspirates and peripheral blood by polymerase chain reaction (PCR), with some series giving a sensitivity of $70-93 \%$ in peripheral blood. ${ }^{10}$ High sensitivities down to the level of one parasite have been recorded. ${ }^{32}$ Newer methods with high sensitivity and specificity include the detection of Leishmania antigen and antibody in the urine. $^{33} 34$

\section{Cutaneous leishmaniasis}

Diagnosis is usually based on microscopic examination of skin scrapings or biopsy specimens, usually taken from the edge of lesions. This is rapid and low-cost, but has limited sensitivity, especially in chronic lesions. ${ }^{35}$

Cultures of the lesions, while more sensitive, may become contaminated by bacterial and fungal elements in the biopsy specimen itself. Also, different species have different growth requirements. Leishmania species may be identified using isoenzyme electrophoresis, but this is lengthy and expensive and necessitates cultivation of parasites on a large scale. Monoclonal antibodies can also be used for identification of

Table 4 Diagnostic methods

\begin{tabular}{|c|c|}
\hline Diagnostic test & Comments \\
\hline \multicolumn{2}{|l|}{ Visceral leishmaniasis } \\
\hline $\begin{array}{l}\text { Microscopic detection of amastigotes in smears of tissue } \\
\text { aspirates or biopsy samples }\end{array}$ & $\begin{array}{l}\text { Bone marrow aspirates or biopsy: sensitivity } 55-97 \% \\
\text { Lymph node aspirate smears (sensitivity } 60 \% \text { ) or biopsy } \\
\text { Splenic aspirates (sensitivity }>97 \% \text { ): risk of life-threatening haemorrhage }\end{array}$ \\
\hline Tissue culture & $\begin{array}{l}\text { On special media like Novy, McNeal, Nicolle (NNN) medium or inoculated into animals such as } \\
\text { hamsters }\end{array}$ \\
\hline Leishmania antibody (DAT) & $\begin{array}{l}\text { Sensitivity } 72 \% \text {, specificity } 94 \% \\
\text { Some cross-reactions in leprosy, Chagas disease, malaria, and schistosomiasis } \\
\text { In HIV, may be falsely negative }\end{array}$ \\
\hline Anti-K39 antibody in blood droplet & $\begin{array}{l}\text { Sensitivity } 90-100 \% \text { in symptomatic patients } \\
\text { Useful in clinical management in resource-poor areas }\end{array}$ \\
\hline $\begin{array}{l}\text { Leishmania DNA detection in tissue aspirates and peripheral } \\
\text { blood by PCR }\end{array}$ & Sensitivity $70-93 \%$ in peripheral blood \\
\hline Detection of Leishmania antigen and antibody in the urine & High sensitivity and specificity \\
\hline \multicolumn{2}{|l|}{ Cutaneous leishmaniasis } \\
\hline $\begin{array}{l}\text { Microscopic examination of skin scrapings or biopsy } \\
\text { specimens taken from the edge of lesions }\end{array}$ & $\begin{array}{l}\text { Rapid and low-cost } \\
\text { Limited sensitivity, especially in chronic lesions } \\
\text { A practical guide to diagnostic techniques in cutaneous leishmaniasis can be found at: http:// } \\
\text { www.thelancet.com/journals/lancet/article/PIIS0140673698101782/fulltext\#abstract }\end{array}$ \\
\hline Cultures of the lesions & $\begin{array}{l}\text { More sensitive than microscopy } \\
\text { May become contaminated } \\
\text { Different species have different growth requirements }\end{array}$ \\
\hline Antibody detection & $\begin{array}{l}\text { Poorly sensitive } \\
\text { In American cutaneous leishmaniasis there have been reports of cross-reactivity }\end{array}$ \\
\hline Montenegro (leishmanin) skin test & $\begin{array}{l}\text { Unable to distinguish between current and past infection } \\
\text { Reports of false positivity in other skin infections }\end{array}$ \\
\hline
\end{tabular}


species in cultured strains, but direct analysis of clinical specimens is better achieved by using PCR, which is rapid, with high specificity and sensitivity. Detection and genetic characterisation of Leishmania can also be accomplished simultaneously. ${ }^{35}$. One study on American cutaneous leishmaniasis yielded a PCR sensitivity rate of $100 \%{ }^{36}$

Antibody detection is poorly sensitive due to a lack of significant antibody production in cutaneous leishmaniasis. Moreover, in American cutaneous leishmaniasis there have been reports of cross-reactivity of leishmanial antigens with antibodies induced by other kinetoplastids such as Trypanosoma cruzi. $^{37}$

Other available means of diagnosing cutaneous leishmaniasis include the Montenegro (leishmanin) skin test which detects specific cutaneous delayed-type hypersensitivity. It involves intradermal injection of Leishmania antigen, for example $L$ Mexicana, and monitoring for a local reaction. ${ }^{38}$ Limitations of this test include its inability to distinguish between current and past infection, as well as reports of false positivity in other skin infections. ${ }^{39}$

\section{TREATMENT}

Recommended treatment regimens are summarised in table 5.

\section{Visceral leishmaniasis}

Treatment is largely based on pentavalent antimonials. Increasing resistance to antimonials is a major problem, and this is most evident in North Bihar, India, where the failure rate for this treatment is more than 50\%. ${ }^{11}{ }^{40}$ Pentavalent antimony $(\mathrm{Sb}(\mathrm{V}))$ can take the form of sodium stibogluconate $(\mathrm{Sb}(\mathrm{V})$ $100 \mathrm{mg} / \mathrm{ml}$ ) or meglumine antimonate $(\mathrm{Sb}(\mathrm{V}) \quad 85 \mathrm{mg} / \mathrm{ml})$. These can be given intravenously or intramuscularly with equal efficacy. It is usually administered at a dose of $\mathrm{Sb}(\mathrm{V}) 20 \mathrm{mg} / \mathrm{kg}$ for 28 days, depending on the species and the clinical syndrome. A recent randomised trial in US military personnel showed a shorter, 10-day course to be equally effective. ${ }^{41} \mathrm{~A}$ maximum dose of $850 \mathrm{mg}$ daily has been recommended ${ }^{42}$ in order to minimise side effects such as arrhythmias. Some experts, however, feel that this might predispose to resistance, and advocate higher doses. In some resistant cases of both visceral leishmaniasis and cutaneous leishmaniasis, IFNgamma has been added successfully to $\mathrm{Sb}(\mathrm{V})$ to induce remission. ${ }^{43}$

Amphotericin B is an effective treatment used in $\mathrm{Sb}(\mathrm{V})$ resistant cases. It is toxic and needs to be given for a prolonged period on an inpatient basis. The alternative is to use the liposomal form, which is highly effective and less toxic, although up to now prohibitively expensive. The trend in Southern Europe is shifting towards using liposomal amphotericin $\mathrm{B}$ as first-line treatment, even though the response rate is still around $90 \%$ for antimonials. However, a recent trend in increasing resistance to pentavalent antimonials in this area has been recorded, possibly attributed to using meglumine antimonate to treat infected dogs. ${ }^{44}$ The effectiveness of short courses of this liposomal amphotericin B is resulting in improved cost-benefits. ${ }^{40}{ }^{45}$ Studies using lower doses of this agent are also showing promise to improve cost-effective treatment in resource poor areas with high antimonial resistance. ${ }^{46}$

Miltefosine is the first effective orally active drug against leishmaniasis. Studies of treatment with this drug for 3 or 4 weeks have shown a cure rate of $95-100 \% .{ }^{47} 48$ It has also compared very well (cure rate of $94 \%$ ) with amphotericin B (cure rate 97\%) at 6 months' follow-up. It has the added benefit of a very good safety profile. ${ }^{49}$ The potential for this drug for treatment of large numbers of patients as outpatients in resource-poor areas is high, though concerns about compliance and eventual resistance have been expressed. ${ }^{11}$
Other effective drugs have been used in treating leishmaniasis. Pentamidine can be used in treatment-resistant cases of visceral leishmaniasis. ${ }^{50}$ Its use is limited by its substantial toxicity, necessitating close inpatient monitoring. ${ }^{51}$ Paromomycin (aminosidine) has been used effectively in resistant cases in North Bihar. ${ }^{52}$ Pending commercial availability, this treatment should offer cost savings, though issues of potential toxicity such as nephrotoxicity or ototoxicity may need further evaluation..$^{53}$ Sitamaquine, another oral agent, is currently being evaluated in phase II studies in India. ${ }^{11}$ This drug has been associated with a 50-67\% cure rate. ${ }^{54}{ }^{55}$ The imidazole and triazole drugs are not recommended for use in visceral leishmaniasis.

In PKDL, treatment is indicated only for those who have severe and prolonged disease. Pentavalent antimonials (2month course usually sufficient) and liposomal amphotericin B are both effective. ${ }^{20}$

\section{Cutaneous leishmaniasis}

In deciding the best mode of treatment of cutaneous leishmaniasis, some facts need to be considered. Old World cutaneous leishmaniasis is not a life threatening disease and $>90 \%$ of patients heal spontaneously within 3-18 months. The outcome of cutaneous leishmaniasis in the New World depends on the infecting species and may vary from benign to more severe manifestations. It is thus important to try to identify the infecting species, either by knowing the endemic species of the specific geographical area, or by means of diagnostic procedures. This can throw light on the prognosis and management options.

Treatment of cutaneous leishmaniasis will accelerate cure and reduce scarring. This is especially important at cosmetically important sites. Options in the treatment of cutaneous leishmaniasis include local or systemic treatment. Criteria in favour of local treatment ${ }^{56}$ include: Old World cutaneous leishmaniasis; small, single lesions; lack of risk of development of mucocutaneous leishmaniasis, lack of lymph node metastases; and $L$ mexicana lesions. New World lesions except $L$ mexicana, mucosal or lymph node involvement and lesions refractory to local treatment would be indications for systemic treatment.

\section{Local treatment of cutaneous leishmaniasis}

Physical modes of treatment including cryotherapy have been employed with success ranging from $77 \%$ to $100 \%$ at 4 weeks. ${ }^{57}$ Local infrared heat lamps have also produced good results, although invariably accompanied by skin bulla formation. ${ }^{59}$

Paromomycin (aminosidine) ointment is produced in two different formulations. When combined with methylbenzethonium chloride, it gives cure rates of $74-85 \%$, which is more effective than when combined with urea. ${ }^{60}$ However, paromomycin-methylbenzethonium causes more severe local inflammatory reactions than paromomycin-urea. ${ }^{61}$

Intralesional infiltration of the dermis and base of the lesion with pentavalent antimony may be performed. This is a relatively painful procedure which needs to be performed regularly every $1-2$ weeks for about 3-8 times. The cure rate with this procedure is about $75 \% .{ }^{11}$ If this is not effective, systemic therapy should be considered.

Imiquimod, a topical immunomodulator has been successfully used in combination with meglumine antimonate in cases resistant to meglumine alone. ${ }^{62}$

\section{Systemic treatment of cutaneous leishmaniasis}

Systemic treatment with antimonials in general requires a 20 day course. $L$ major, $L$ tropica and $L$ mexicana usually respond to a 10-day course. ${ }^{11}$ Pentamidine has been used as first line 
Table 5 Summary of recommended treatment regimens*

\begin{tabular}{|c|c|c|c|}
\hline Disease pattern & Drug & Dose & Comments† \\
\hline $\begin{array}{l}\text { Visceral } \\
\text { leishmaniasis }\end{array}$ & $\begin{array}{l}\text { Pentavalent antimony (as stibogluconate } \\
\text { or meglumine antimonate) } \\
\text { Liposomal amphotericin B } \\
\text { Miltefosine }\end{array}$ & $\begin{array}{l}20 \mathrm{mg} / \mathrm{kg} / \text { day } \mathrm{IM} \text { or IV } \times 28 \text { days } \\
2 \mathrm{mg} / \mathrm{kg} / \text { day IV } \times 5 \text { days } \\
2.5 \mathrm{mg} / \mathrm{kg} / \text { day } P O \text { (od or bd) } \times 28 \text { days }\end{array}$ & $\begin{array}{l}\text { Some experts advise not to exceed } 850 \text { mg daily } \\
\text { Not effective in North Bihar, India } \\
\text { (A) } \\
\text { (A) }\end{array}$ \\
\hline $\begin{array}{l}\text { Mucocutaneous } \\
\text { leishmaniasis }\end{array}$ & $\begin{array}{l}\text { As with visceral leishmaniasis } \\
\text { Amphotericin B }\end{array}$ & $1 \mathrm{mg} / \mathrm{kg}$ IV qod $\times 20-30$ doses & $\begin{array}{l}\text { This may be better than antimonials in mucosal } \\
\text { disease }\end{array}$ \\
\hline $\begin{array}{l}\text { Cutaneous } \\
\text { leishmaniasis }\end{array}$ & $\begin{array}{l}\text { Observation alone } \\
\text { Pentavalent antimony (as stibogluconate } \\
\text { or meglumine antimonate) } \\
\text { Fluconazole } \\
\text { Ketoconazole } \\
\text { Miltefosine } \\
\text { Pentavalent antimony } \\
\text { Pentamidine } \\
\text { Paromomycin }\end{array}$ & $\begin{array}{l}20 \mathrm{mg} / \mathrm{kg} / \text { day IM or IV } \times 20 \text { days ( } \times 10 \text { days } \\
\text { in } L \text { major, } L \text { tropica and } L \text { mexicana) } \\
200 \mathrm{mg} \text { PO od } \\
600 \mathrm{mg} \mathrm{PO} \text { od } \times 28 \text { days } \\
2.5 \mathrm{mg} / \mathrm{kg} \text { PO od } \times 28 \text { days } \\
\text { Intralesional: } 1 \mathrm{ml} \text { per lesion qod } \times 8-15 \text { times } \\
2-4 \mathrm{mg} / \mathrm{kg} \text { od or every } 2 \text { days IV } \times 15 \text { doses } \\
\text { Topical bd }\end{array}$ & $\begin{array}{l}L \text { major }(A) \text { and } L \text { mexicana }(B) \\
\text { Some experts advise not to exceed } 850 \mathrm{mg} \text { daily } \\
\text { vs } L \text { major }(A) \\
\text { vs } L \text { panamensis }(A) \\
\text { vs } L \text { mexicana }(A) \\
\text { vs } L \text { panamensis }(A) \\
\text { vs } L \text { major every } 1-2 \text { weeks } \times 3-8 \text { times }(A) \\
\text { vs } L \text { tropica weekly } \times 8-11 \text { times }(D) \\
\text { vs } L \text { panamensis and } L \text { braziliensis } \\
\text { vs } L \text { guyanensis }(C) \\
\text { vs } L \text { major } \times 4 \text { weeks }(A) \\
\text { vs } L \text { mexicana } \times 20 \text { days }(B)\end{array}$ \\
\hline
\end{tabular}

bd, twice daily; IM, intramuscular; IV, intravenous; od, once daily; PO, orally; qod, every other day.

*Adapted from The Sanford Guide to Antimicrobial Therapy, 2005 (35th edition), Murray et al ${ }^{12}$ and Blum et al ${ }^{56}$

tLevel of evidence, when available, in brackets. Grades of recommendations based on best available evidence: (A) Randomised, controlled trial in representative collective. (B) Randomised, controlled trial in partially representative (small patient number, different species included) collective. Cohort trial or case control study in representative collective. (C) Cohort trial or case-control study in partially representative collective, series of cases in representative collective. (D) Series of cases in partially representative (small patient number, different species included) collective, informal expert opinion, other information.

therapy in L guyanensis infection, but studies with $L$ panamensis, $L$ brasiliensis and L mexicana have also given a cure rate of $96 \%$, comparable to $91 \%$ with meglumine antimonate. ${ }^{63} 64$

Of the imidazole/triazole drugs, oral fluconazole and has been found useful in $L$ major infections, with a cure rate of $79 \% .{ }^{65}$ Ketoconazole has been studied in $L$ braziliensis panamensis with efficacy $(74 \%)$ similar to that of stibogluconate $(68 \%){ }^{66}$

Oral miltefosine has been studied in Colombia and Guatemala, with short-term cure rates of $91 \%$ in areas where $L(V)$ panamensis is common. In areas where $L(V)$ braziliensis and $L$ mexicana mexicana are common, the cure rate fell to $53 \%{ }^{67}$

Liposomal amphotericin B has not been extensively studied in cutaneous leishmaniasis, but isolated reports of its use in resistant cases show its effectiveness. ${ }^{68}{ }^{69}$ Similarly, systemic aminosidine has not been commonly used, and a study comparing it to antimonials for $L$ braziliensis cutaneous leishmaniasis was not in favour of its use in this form. ${ }^{70}$

Allopurinol has shown some enhancing of antimonial activity, but its use alone has not shown any significant benefit. $^{71}$

\section{Mucocutaneous leishmaniasis}

Treatment of mucocutaneous leishmaniasis with antimonials is unsatisfactory, especially in severe disease. ${ }^{72}$ Amphotericin $\mathrm{B}^{73}$ and more recently liposomal amphotericin B have been used in difficult cases with success. ${ }^{74}$ Steroids may have to be used in cases where respiratory compromise is possible.

\section{Leishmania-HIV coinfection}

There needs to be a high index of suspicion in patients with HIV with the typical presentations of visceral leishmaniasis such as pyrexia, pancytopenia and hepatosplenomegaly. However, splenomegaly may be absent in HIV. ${ }^{75}$ Uncommon sites of infection, such as the gastrointestinal tract or the upper respiratory tract, are more frequent. Diagnosis is reached as for non-HIV patients except that the Leishmania antibody test (direct agglutination test) is frequently $(42.6 \%)$ negative. ${ }^{76} 77$ The highest prevalence of coinfection occurs in southwestern
Europe, mostly in Spain. ${ }^{76}$ The main risk group is intravenous drug users and an anthroponotic cycle has been suggested where Leishmania organisms present in used syringes ${ }^{78}$ are inoculated intravenously.

The importance of cell-mediated immunity in controlling leishmaniasis in the long term is best illustrated in LeishmaniaHIV coinfection. When visceral leishmaniasis occurs in a known HIV-positive patients or when someone with a history of visceral leishmaniasis acquires HIV, there is a high risk that the Leishmania infection will become intractable. Even after appropriate treatment of visceral leishmaniasis, LeishmaniaHIV is associated with a high relapse rate of $52 \%$ after 1 month to 3 years. $^{76}$ Visceral leishmaniasis in HIV infection is being proposed for inclusion in the Centers for Disease Control and Prevention CDC clinical category $\mathrm{C}$ for the definition of AIDS as an indicator disease. ${ }^{79}$

Although treatment of coinfection has not been adequately studied, pentavalent antimonials are still used widely. The relapse rate does not appear to be affected by the type of treatment given according to a head-to-head study between meglumine antimonate and amphotericin $\mathrm{B}^{80}$ Meglumine antimonate and liposomal amphotericin have only been compared in smaller studies; no differences were found. ${ }^{81}$ One study suggested a role for oral miltefosine when the above treatments have failed in coinfected individuals. ${ }^{82}$

Secondary prophylaxis prevents relapse and improves survival. $^{79}{ }^{83}$ Both pentavalent antimonials administered once every 28 days $^{84}$ and liposomal amphotericin B every 21 days may be used; ${ }^{83}$ no differences in efficacy have been found. Secondary prophylaxis should be continued at CD4 counts below 200/ $\mu$ l. It may be safe to stop secondary prophylaxis at CD4 counts above $350 / \mu \mathrm{l}$ and possibly even above $200 / \mu \mathrm{l}$ while on effective antiretroviral treatment. ${ }^{84}$ Antiretroviral treatment has been effective in decreasing relapses of visceral leishmaniasis. ${ }^{85}$

\section{CONTROL}

Control of leishmaniasis depends on the prevalent local epidemiological characteristics. Thus in areas where sandflies 


\section{Key references}

- Murray HW, Berman JD, Davies CR, et al. Advances in leishmaniasis. Lancet 2005;366:1561-77.

- Davies CR, Kaye P, Croft SL, et al. Leishmaniasis: new approaches to disease control. BMJ 2003;326:377-82.

- Guerin PJ, Olliaro P, Sundar S, et al. Visceral leishmaniasis: current status of control, diagnosis, and treatment, and a proposed research and development agenda. Lancet Infect Dis 2002;2:494-501.

- Herwaldt BL. Leishmaniasis. Lancet 1999;354:1191-9.

- Paredes R, Munoz J, Diaz I, et al. Symposium: Leishmaniasis in HIV infection. J Postgrad Med 2003;49:39-49.

are mostly endophilic (rest mostly indoors after feeding), spraying houses with insecticide is effective in reducing the likelihood of contracting cutaneous leishmaniasis. ${ }^{86} 87$ Treated and untreated bed nets have been used effectively in environments where sandflies are endophagic (feed mainly indoors). ${ }^{88}$ In some areas where the disease is transmitted anthroponotically, nets have also been used to prevent transmission from infected patients with cutaneous leishmaniasis. Other control strategies, including insecticide impregnated curtains, and insecticide treatment of dogs and dog collars have been used with good effect. ${ }^{89}$

In Brazil, dogs are culled if they test positive for Leishmania, but this strategy has not been effective. ${ }^{90}$ In southwestern Europe, where leishmaniasis is closely linked with intravenous drug abuse and HIV, control of HIV has yielded positive results. ${ }^{91}$ Needle-exchange interventions should have similar results.

In India, where anthroponotic transmission is important, effective treatment of patients, especially those with PKDL (who may act as long-term reservoirs), has been found to be effective in controlling transmission when combined with vector control. ${ }^{2}$

There is no effective vaccine for prevention of leishmaniasis. The closest effective alternative to vaccination follows from the traditional "leishmanisation" technique adopted in the Middle East and Eastern Europe. This involved the encouragement of sandfly bites on traditionally unexposed areas of skin, such as the buttocks. The resulting lesion would heal spontaneously, in the process providing immunity against cutaneous leishmaniasis in less acceptable areas, such as the face. Early studies recommended using $L$ tropica inoculations to induce immunity. ${ }^{92}$ This technique has been further developed in Iran, where scientists have produced standardised and stable $L$ major populations which can produce more consistent and acceptable iatrogenically-induced lesions. ${ }^{89}$

The safety and efficacy of live-attenuated and killed vaccines has been debated and shifts in favour of development some of these has been recorded in recent years. Killed vaccines were favoured in the 1990s because of safety problems with liveattenuated vaccines; however, recent advances in manipulation of the Leishmania genome may make development of a live attenuated vaccine more feasible. ${ }^{93}$

Work on recombinant DNA derived antigen vaccines and protein or peptide-based vaccines is a more recent approach, made possible by the Leishmania Genome Project (www. sanger.ac.uk/Projects/L major/). The realisation that CD8 cells are as important as $\bar{C}$ 4 4 cells in inducing resistance ${ }^{94}$ and maintaining immunity has led to a shift in vaccine research. ${ }^{95}$
Most vaccine research is targeted against cutaneous leishmaniasis; any effectiveness against visceral leishmaniasis is uncertain. Work on a vaccine against human visceral leishmaniasis has been less successful, ${ }^{96}$ but should be boosted following success with a cutaneous leishmaniasis vaccine. Work on a canine visceral leishmaniasis vaccine seems to be more advanced. ${ }^{97}$

\section{CONCLUSION}

Leishmaniasis remains a problematic infection requiring either potentially toxic treatments or less toxic, but expensive drugs. However, the availability of newer oral agents may change the way this disease is managed. Relapse may occur, especially in situations where immunosuppression is present; secondary prophylaxis needs to be given in this setting. The combination of Leishmania, HIV and anthroponotic transmission between injecting drug users heralds a potential for higher incidence rates in endemic countries with severe drug abuse problems. In the absence of an effective vaccine, and with extension of endemicity, possibly due to climate change, these problems may become worse.

\section{MULTIPLE CHOICE QUESTIONS (TRUE/FALSE (T/F); ANSWERS AT END OF REFERENCES)}

1. Epidemiology

(A) Leishmania is endemic in Australasia

(B) Leishmania can be transmiited through infected syringes

(C) The epidemiology of Leishmania is tightly knit with the epidemiology of the sandfly

(D) The sandfly usually bites during the day

(E) The number of countries where Leishmania is endemic is set to increase with global warming

2. Visceral leishmaniasis

(A) Is characterised by splenomegaly and pancytopenia

(B) Carries a low mortality if not treated

(C) The organism is characteristically extracellular

(D) Fatalities are usually the result of secondary bacterial infections

(E) Almost always responds to antimony products

3. Immunology

(A) An effective vaccine is available

(B) The body's response to infection is T-cell mediated

(C) The disease manifestation depends on Leishmania species and host response

(D) Immunosuppression predisposes to Leishmania infection

(E) Leishmania organisms can remain dormant for years in the reticulo-endothelial system

\section{Treatment}

(A) Liposomal amphotericin is effective but very expensive

(B) There are no oral medications to effectively treat Leishmania

(C) Oral miltofisine is very effective in the treatment of kala azar

(D) Cutaneous Leishmania can be treated both by physical and pharmacological means

(E) Leishmania in the immunosuppressed usually necessitates secondary prophylaxis 


\section{Diagnosis}

(A) Identification of amastigotes in tissue smears or histology are commonly used methods of diagnosis

(B) Antibody towards K39 antigen is proving useful, especially in field diagnosis of visceral leishmaniasis

(C) Tissue cultures are used routinely

(D) Splenic aspirates are very sensitive and usually safe

(E) Leishmania PCR is useless on blood samples

\section{ACKNOWLEDGEMENT}

We are grateful to Dr Paul Cuschieri, Consultant Microbiologist St Luke's Hospital, Malta, for his helpful comments during production of this review.

\section{Authors' affiliations}

C Mallia Azzopardi, T V Piscopo, St Luke's Hospital, Guardamangia Hill, Guardamangia, Malta

Competing interests: None.

\section{REFERENCES}

1 Murray HW. Kala-azar-progress against a neglected disease. N Engl J Med 2002;22:1793-4.

2 Guerin PJ, Olliaro P, Sundar S, et al. Visceral leishmaniasis: current status of control, diagnosis, and treatment, and a proposed research and development agenda. Lancet Infect Dis 2002;2:494-501.

3 Desjeux P. Leishmaniasis: current situation and new perspectives. Comp Immunol Microbiol Infect Dis 2004; 27:305-18.

4 Herwaldt BL Leishmaniasis, Lancet 1999-354:1191-9.

5 Arias JR, Monteiro PS, Zicker F. The re-emergence of visceral leishmaniasis in Brazil. Emerg Infect Dis 1996;2:145-6.

6 Desjeux $\mathbf{P}$. The increase in risk factors for leishmaniasis worldwide. Trans $R$ Soc Trop Med Hyg 2001;95:239-43.

7 Kuhn KG. Global warming and leishmaniasis in Italy. Bull Trop Med Int Health 1999;7:1-2.

8 Hsia R. Leishmaniasis. 2005. http://www.emedicine.com/emerg/topic296.htm.

9 Lainson R, Shaw JJ. Evolution, classification and geographic distribution. In: Peters W, Killick-Kendrick R, eds. The leishmaniases in biology and medicine. V.1. London: Academic Press, 1987:1-120.

10 Zijlstra EE, El-Hassan AM. Visceral leishmaniasis. Trans R Soc Trop Med Hyg 2001;95(Suppl 1):S27-58.

11 Murray HW, Berman JD, Davies CR, et al. Advances in leishmaniasis. Lancet 2005;366:1561-77

12 Mandell GL, Bennett JE, Dolin R. Mandell, Douglas and Bennett's principles and practice of infectious diseases, 6th edn. Philadelphia, PA: Elsevier Churchill Livingstone, 2005:2428-42.

13 Grech V, Mizzi J, Mangion M, et al. Visceral leishmaniasis in Malta-an 18 year paediatric, population based study. Arch Dis Child 2000;82:381-5.

14 Gradoni L, Gramiccia M, Léger N et al. Isoenzyme characterization of Leishmania from man, dog and sandflies in the Maltese islands. Trans $R$ Soc Trop Med Hyg 1991;85:217-19.

15 De Alencar JE, Neves J. Leishmaniose visceral (calazar). In: Veronesi R, ed. Doencas Infecciosas e Parasitarias, 7th edn. Rio de Janeiro: Editora Guanabara Koogan SA, 1982:724.

16 Manson-Bahr PEC, Southgate BA, Harvey AEC. Development of kala-azar in man after inoculation with a leishmania from a Kenyo sandfly. BMJ 1963;1:1208-10

17 Manson-Bahr PEC, Apted FIC. Leishmaniasis. In: Manson-Bahr PEC, Apted FIC, eds. Manson's tropical diseases, 18th edn. London: Bailliere Tindall, 1982:93-115.

18 Stone HH, Tool CD, Pugsley WS. Kala-azar (visceral leishmanisis): report of a case with 34 month incubation period and positive Doan-Wright test. Ann Intern Med 1952;36:686-93.

19 Wilson ME, Streit JA. Visceral leishmaniasis. Gastroenterol Clin North Am 1996;25:535-51.

20 Zijlstra E E, El-Hassan AM. Post kala-azar dermal leishmaniasis. Trans $R$ Soc Trop Med Hyg 2001;95(Supp 1):S59-76.

21 Smith PAJ. Long incubation period in leishmaniasis. BMJ 1955:2:1143.

22 Marsden PD, Nonata RR. Mucocutaneous leishmaniasis-a review of clinical aspects. Rev Soc Bras Med Trop 1975;9:309-26.

23 Stark CG, Wortmann G. Leishmaniasis. http://www.emedicine.com/MED/ topic 1275. htm.

24 Heinzel FP, Sadick MD, Holaday BJ, et al. Reciprocal expression of interferon gamma or interleukin 4 during the resolution or progression of murine leishmaniasis. Evidence for expansion of distinct helper T cell subsets. J Exp Med 1989; 169:59-72.

25 Reiner SL, Wang ZE, Hatam F, et al. TH1 and TH2 cell antigen receptors in experimental leishmaniasis. Science 1993;259:1457-60.
26 Reed SG, Scott P. T-cell and cytokine responses in leishmaniasis. Curr Opin Immunol 1993;5:524-31.

27 Sundar S, Reed SG, Sharma S, et al. Circulating T helper 1 (TH1) cell- and TH2 cell-associated cytokines in Indian patients with visceral leishmaniasis. Am J Trop Med Hyg 1997;56:522-5.

28 Roberts LJ, Handman E, Foote SJ. Leishmaniasis. BMJ 2000;321:801-4.

29 Costa CHN, Stewart JM, Gomes RBB, et al. Asymptomatic human carriers of Leishmania chagasi. Am J Trop Med Hyg 2002;66:334-7.

30 Dereure J, Duong Thanhb H, et al. Visceral leishmaniasis. Persistence of parasites in lymph nodes after clinical cure. J Infect 2003;47:77-81.

31 Sundar S, Sahu M, Mehta H, et al. Noninvasive management of Indian visceral leishmaniasis: clinical application of diagnosis by K39 antigen strip testing at a kala-azar referral unit. Clin Infect Dis 2002;35:581-6.

32 Salotra P, Sreenivas G, Pogue GP, et al. Development of a species-specific PCR assay for detection of Leishmania donovani in clinical samples from patients with kala-azar and post-kala-azar dermal leishmaniasis. J Clin Microbiol 2001;39:849-54

33 Sundar S, Agrawal S, Pai K, et al. Detection of leishmanial antigen in the urine of patients with visceral leishmaniasis by latex agglutination test. Am J Trop Med Hyg 2005;73:268-71.

34 Islam $M Z$, Itoh $M$, Mirza $R$, et al. Direct agglutination test with urine samples for the diagnosis of visceral leishmaniasis. Am J Trop Med Hyg 2004;70:78-82.

35 Belli A. Simplified polymerase chain reaction detection of new world Leishmania in clinical specimens of cutaneous leishmaniasis. Am J Trop Med Hyg 1998:58:102-9

36 de Oliveira $\mathrm{Cl}$, Bafica $\mathrm{A}$, Oliveira $\mathrm{F}$, et al. Clinical utility of polymerase chain reaction-based detection of Leishmania in the diagnosis of American cutaneous leishmaniasis. Clin Infect Dis 2003:37:el 49-53.

37 Camargo ME, Rebonato C. Cross-reactivity in immuno-fluorescence test for Trypanosoma and Leishmania antibodies. A simple inhibition procedure to ensure specific results. Am J Trop Med Hyg 1969;18:500-5.

38 Lugo de yarbuh A. Studies of the leishmanin skin test positivity in cases with treatment anti-leishmania. Parasitol Día 1997:21(3-4):76-80.

39 de Lima Barros MB, Schubach A, Francesconi-do-Valle AC, et al. Positive Montenegro skin test among patients with sporotrichosis in Rio De Janeiro. Acto Trop 2005;93:41-7.

40 Sundar S, Jha TK, Thakur CP, et al. Single-dose liposomal amphotericin B in the treatment of visceral leishmaniasis in India: a multicenter study. Clin Infect Dis 2003;37:800-4

41 Wortmann G, Miller RS, Oster C, et al. A randomized, double-blind study of the efficacy of a 10- or 20-day course of sodium stibogluconate for treatment of cutaneous leishmaniasis in United States military personnel. Clin Infect Dis 2002:35:261-7.

42 World Health Organization. Control of the leishmaniasis, WHO Technical Report Series, 293. Geneva: WHO, 1990.

43 Gallin JI, Farber JM, Holland SM, et al. Interferon-gamma in the management of infectious diseases. Ann Intern Med 1995;123:216-24.

44 Gradoni L, Gramiccia M, Scalone A. Visceral leishmaniasis treatment, Italy. Emerg Infect Dis, 2003 Dec.http://www.cdc.gov/ncidod/EID/vol9no12/ 03-0178.htm.

45 Syriopoulou V, Daikos GL, Theodoridou M, et al. Two doses of a lipid formulation of amphotericin $B$ for the treatment of Mediterranean visceral leishmaniasis. Clin Infect Dis 2003;36:560-6.

46 Sundar S, Agrawal G, Rai M, et al. Treatment of Indian visceral leishmaniasis with single or daily infusions of low dose liposomal amphotericin $\mathrm{B}$ : randomised trial. BMJ 2001;323:419-22.

47 Sundar S, Makharia A, More DK, et al. Short-course of oral miltefosine for treatment of visceral leishmaniasis. Clin Infect Dis 2000;31:1110-13.

48 Jha TK, Sundar S, Thakur CP, et al. Miltefosine, an oral agent, for the treatment of Indian visceral leishmaniasis. N Engl J Med 1999;341:1795-800.

49 Sundar S, Jha TK, Thakur CP, et al. Oral miltefosine for Indian visceral leishmaniasis. N Engl J Med 2002;347:1739-46.

50 Sinha PK, Ranjan A, Singh VP, et al. Visceral leishmaniasis (kala-azar)-the Bihar (India) perspective. J Infect 2005;doi;10.1016/j.jinf.2005.09.011

51 Jha TK. Evaluation of diamidine compound (pentamidine isethionate) in the treatment resistant cases of kala-azar occurring in North Bihar, India. Trans R Soc Trop Med Hyg 1983;77:167-70.

52 Jha TK. Randomised controlled trial of aminosidine (paromomycin) $v$ sodium stibogluconate for treating visceral leishmaniasis in North Bihar, India. BMJ 1998;316:1200-5

53 Rosenthal E, Marty P. Recent understanding in the treatment of visceral leishmaniasis. J Postgrad Med, 2003;49, 1:61-8.

54 Sherwood JA, Gachihi GS, Muiggai RK, et al. Phase 2 efficacy trial of an oral 8aminoquinoline (WR6026) for treatment of visceral leishmaniasis. Clin Infect Dis 1994:19:1034-9.

55 Dietze R, Carvalho SF, Valli LC, et al. Phase 2 trial of WR6026, an orally administered 8-aminoquinoline, in the treatment of visceral leishmaniasis caused by Leishmania chagasi. Am J Trop Med Hyg 2001;65:685-9.

56 Blum J, Desjeux, Schwartz E, et al. Treatment of cutaneous leishmaniasis among travellers. J Antimicrob Chemother 2004;53:158-66.

57 Bassiouny A, El Meshad M, Talaat $M$, et al. Cryosurgery in cutaneous leishmaniasis. Br J Dermatol 1982;107:467-74.

58 Gurei MS, Tatli N, Ozbilge H, et al. Efficacy of cryotherapy and intralesiona pentostam in treatment of cutaneous leishmaniasis. J Egypt Soc Parasitol 2000;30: 169-76.

59 Junaid AJ. Treatment of cutaneous leishmaniasis with infrared heat. Int J Dermato 1986;25:470-2.

60 Garnier T, Croft L. Topical treatment for cutaneous leishmaniasis. Curr Opin Investig Drugs 2002;3:538-44. 
61 Bryceson AD, Murphy A, Moody AH. Treatment of 'Old World' cutaneous leishmaniasis with aminosidine ointment: results of an open study in London. Trans R Soc Trop Med Hyg 1994;88:226-8.

62 Arevalo I, Ward B, Miller R, et al. Successful treatment of drug-resistant cutaneous leishmaniasis in humans by use of imiquimod, an immunomodulator. Clin Infect Dis 2001;33:1847-51.

63 Soto-Mancipe J, Grogl M, Berman JD. Evaluation of pentamidine for the treatment of cutaneous leishmaniasis in Colombia. Clin Infect Dis 1993:16:417-25

64 Soto J, Buffet P, Grogl M, et al. Successful treatment of Colombian cutaneous leishmaniasis with four injections of pentamidine. Am J Trop Med Hyg 1994;50:107-11

65 Alrajhi AA, Ibrahim EA, De Vol EB, et al. Fluconazole for the treatment of cutaneous leishmaniasis caused by Leishmania major. N Engl J Med 2002;346:891-5.

66 Saenz RE, Paz H, Berman JD. Efficacy of ketoconazole against Leishmania braziliensis panamensis cutaneous leishmaniasis. Am J Med 1990;89:147-55.

67 Soto J, Arana BA, Toledo J, et al. Miltefosine for New World cutaneous leishmaniasis. Clin Infect Dis 2004;38:1266-72.

68 Brown M, Noursadeghi M, Boyle J, et al. Successful liposomal amphotericin B treatment of Leishmania braziliensis cutaneous leishmaniasis. Br J Dermatol 2005; 153:203-5

69 Devlin RK, Parsonnet J, Klaus SN. Treatment of relapsed cutaneous Leishmania (Viannia) braziliensis infection with liposomal amphotericin B. Infect Dis Clin Pract 2005; 13:84-6.

70 Hepburn NC, Tidman MJ, Hunter JAA. Aminosidine (paromomycin) versus sodium stibogluconate for the treatment of American cutaneous leishmaniasis. Trans R Soc Trop Med Hyg 1994:88:700-3.

71 Martinez S, Marr JJ. Allopurinol in the treatment of American cutaneous leishmaniasis. N Engl J Med 1992;326:741-4.

72 Franke ED, Wignall FS, Cruz ME, et al. Efficacy and toxicity of sodium stibogluconate for mucosal leishmaniasis. Ann Intern Med 1990;1 13:934-40.

73 Sampaio SAP, Castro RM, Dillon NL, et al. Treatment of mucocutaneous (American) leishmaniasis with amphotericin B: a report of 70 cases. Int J Dermatol 1971;10:179-81.

74 Amato VS, Nicodemo AC, Amato JG, et al. Mucocutaneous leishmaniasis associated with HIV infection treated successfully with liposomal amphotericin B (AmBisome). J Antimicrob Chemother 2000:46:341-2.

75 Paredes R, Munoz J, Diaz I, et al. Leishmaniasis in HIV infection. J Postgrad Med 2003;49:39-49

76 World Health Organization. The leishmaniasis and Leishmania/HIV coinfections, WHO Fact Sheet no 116. WHO, May, 2000

77 Alvar J, Canavata C, Gutierreez-Solar B, et al. Leishmania and human immunodeficiency virus co-infection: the first 10 years. Clin Microbiol Rev 1997; 10:298-319.

78 Cruz I, Morales MA, Noguer I, et al. Leishmania in discarded syringes from intravenous drug users. Lancet 2002;359:1124-5.

79 Pasquau F, Ena J, Sanchez R, et al. , Leishmania HIV Mediterranean Cooperative Group. Leishmaniasis as an opportunistic infection in HIV-infected patients: determinants of relapse and mortality in a collaborative study of 228 episodes in a Mediterranean region. Eur J Clin Microbiol Infect Dis 2005;24:411-18.

80 Laguna $F$, López-Vélez R, Pulido F, et al. Treatment of visceral leishmaniasis in HIV-infected patients: a randomized trial comparing meglumine antimoniate with amphotericin B. AIDS 1999;13:1063-70.
81 Goldsmith DR, Perry CM. Amphotericin B lipid complex: in visceral leishmaniasis. Drugs 2004;64:1905-13.

82 Sindermann H, Engel KR, Fischer C, et al. The Miltefosine Compassionate Use Program. Oral miltefosine for leishmaniasis in immunocompromised patients: compassionate use in 39 patients with HIV infection. Clin Infect Dis 2004;39:1520-3

83 Lopez-Velez R, Videla S, Marquez M, et al. Spanish HIV-Leishmania Study Group. Amphotericin B lipid complex versus no treatment in the secondary prophylaxis of visceral leishmaniasis in HIV-infected patients. J Antimicrob Chemother 2004:53:540-3.

84 Berenguer J, Cosín J, Miralles P, et al. Discontinuation of secondary antiLeishmania prophylaxis in HIV-infected patients who have responded to highly active antiretroviral therapy. AIDS 2000;14:2946-8.

85 Russo R, Nigro L, Panarello G, et al. Clinical survey of Leishmania/HIV co infection in Catania, Italy: the impact of highly active antiretroviral therapy (HAART). Ann Trop Med Parasitol 2003;97(Suppl 1):149-55.

86 Reyburn H, Ashford R, Mohsen M, et al. A randomized controlled trial of insecticide-treated bednets and chaddars or top sheets, and residual spraying of interior rooms for the prevention of cutaneous leishmaniasis in Kabul, Afghanistan. Trans R Soc Trop Med Hyg 2000;94:361-6.

87 Davies CR, Llanos-Cuentas EA, Campos P, et al. Spraying houses in the Peruvian Andes with lambda-cyhalothrin protects residents against cutaneous leishmaniasis. Trans R Soc Trop Med Hyg 2000;94:631-6.

88 Bern C, Joshi $A B$, Jha $S N$, et al. Factors associated with visceral leishmaniasis in Nepal: bed-net use is strongly protective. Am J Trop Med Hyg 2000;63:184-8.

89 Davies CR, Kaye P, Croft SL, et al. Leishmaniasis: new approaches to disease control. BMJ 2003;326:377-82.

90 Carlos HN, Costa JM, Stewart RBB, et al. Asymptomatic human carriers of Leishmania chagasi. Am J Trop Med Hyg 2002;66:334-7.

91 del Giudice P, Mary-Krause M, Pradier C, et al. Impact of highly active antiretroviral therapy on the incidence of visceral leishmaniasis in a French cohort of patients infected with HIV. J Infect Dis 2002;186:1366-70.

92 Berberian DA. Vaccination and immunity against oriental sore. Trans $R$ Soc Trop Med Hyg 1939;33:87-8.

93 Handman E. Leishmaniasis: current status of vaccine development. Clin Microbiol Rev 2001; 14:229-43

94 Belkaid Y, Von Stebut E, Mendez S, et al. CD8 + T cells are required for primary immunity in C57BL/6 mice following low-dose, intradermal challenge with Leishmania major. J Immunol 2002;168:3992-4000.

95 Rhee EG, Mendez S, Shah JA, et al. Vaccination with heat-killed Leishmania antigen or recombinant leishmanial protein and $\mathrm{CpG}$ oligodeoxynucleotides induces long-term memory CD4+ and CD8+ T cell responses and protection against Leishmania major infection. J Exp Med 2002·195:1565-73.

96 Khalil EAG, El Hassan AM, Zijlstra EE, et al. Autoclaved Leishmania major vaccine for prevention of visceral leishmaniasis: a randomised, double-blind, BCG-controlled trial in Sudan. Lancet 2000;356:1565-9.

97 Gradoni L. An update on antileishmanial vaccine candidates and prospects for a canine Leishmania vaccine. Vet Parasitol 2001;100:87-103.

\section{ANSWERS}

1. (A) F, (B) T, (C) T, (D) F, (E) T; 2. (A) T, (B) F, (C) F, (D) T, (E) F; 3. (A) F, (B) T, (C) T, (D) T, (E) T; 4. (A) T, (B) F, (C) T, (D) $\mathrm{T}$, (E) T; 5. (A) T, (B) T, (C) F, (D) F, (E) F. 